\title{
APPLICATION OUTSOURCING IN EUROPE: LONG-TERM OUTCOMES, SUCCESS FACTORS AND IMPLICATIONS FOR IT INDUSTRIALIZATION
}

\author{
Karin Kronawitter, Centre for Security, Plymouth University, UK, info@cscan.org \\ Christoph Wentzel, Centre for Security, Plymouth University, UK, info@cscan.org \\ Maria Papadaki, Centre for Security, Plymouth University,UK, info@cscan.org \\ Urs Andelfinger Centre for Security, Plymouth University, UK, info@cscan.org
}

\begin{abstract}
The evolution of the information technology (IT) industry towards industrialization is a widely discussed topic. Will enterprises move permanently towards outsourcing IT services to external vendors who produce standardized IT products for an increasingly large customer group? The dramatic growth of IT-Outsourcing (ITO) points in this direction. However, the success of IT outsourcing is not guaranteed. Only if enterprises are satisfied with their ITOs in the long term, can such schemes become successful. At the moment, there is a lack of research on understanding the success factors and their impact on ITOs. This paper focuses on this research gap and presents the central findings of an intensive analysis of 8 application outsourcing case studies in 5 European banks: applications of different kinds can be successfully outsourced in the long run; Success factors exist which are basically relevant for all ITO cases (general success factors); The relevance of other success factors depends on basic conditions like the organizational form (specific success factors); An ITO model was developed with the aim to aid organizations in planning and implementing ITO solutions and to guide them step-by-step through an ITO project that comprises of the core factors relevant for sustained ITO success.
\end{abstract}

Keywords: IT Application Outsourcing, Long-term Outcomes, Success Factors

\section{INTRODUCTION}

The evolution of the IT industry towards industrialization is a widely discussed topic. In particular, Nicholas Carr [3] first stimulated discussion on the topic IT industrialization almost ten years ago when he suggested that IT had become a commodity, that IT assets were overbuilt and that some companies needed redundant functionality. In his mind, this will lead to the supplementation of today's private IT departments of companies by large-scale, centralised utilities in the future [4]. Industrialization in general is defined as spreading of standardized and highly productive methods in production of goods and services in all economic areas [2]. The key concepts of industrialization are: standardisation, specialization, systematic reuse and automation [1]. These characteristics can only be economically created and fully utilized by companies specialising in a certain economic area with a sufficient source of demand. ITO means "the contractual delegation of IT service provision to an external vendor for a centralized supply" [5]. The core business of an ITO vendor is the production of information technology for a broad customer base. The IT- Outsourcing (ITO) market is growing dramatically, as the figures suggest; the estimated turnover of the global ITO market in 2011 is $\$ 313.2$ billion USD, and the expected annual growth until 2015 is $4.6 \%$ [18].

On the other hand, not all ITO's are successful. Alongside the persistent rise of outsourcing, backsourcing of previously outsourced activities, which means bringing previously outsourced IT functions back in-house [21] and problems with ITO were reported in recent years [10]. In fact, despite the rising number of companies taking up ITO, the chances of success are seen at best 50:50 [13]. Researchers have noted that reported ITO failures might in fact be due to a lack of understanding of the possible success factors [12]. However, these researchers differ regarding factors that distinguish between success and failure [15]. They demand even a specific ITO theory explaining ITO success instead of relying on general management theories which do not fit exactly to the IT sourcing context [14]. It has not been possible to evaluate the success of ITO strategically, particularly in the long 


\section{Issues in Information Systems}

Volume 13, Issue 2, pp. 369-379, 2012

term, due to a lack of data $[7,8,16,17]$. Hence, an ITO model that will identify critical success factors and their implications is needed.

The author took up this research gap in her $\mathrm{PhD}$ thesis and conducted in 2010 a multiple case study of eight successful nearshore and onshore application outsourcing cases in five well-known European banks running already between two und seventeen years. The outcome of the ITOs, the responsible success factors and when the success factors need to be considered within the ITO process were determined. Building on this basis, an ITO model has been developed with the aim to aid organizations in planning and implementing ITO solutions and guide them stepby-step according to the core factors relevant for sustained ITO success. The central findings for researchers and practitioners emerging from this study are:

Finding 1: The outsourcing of applications by European banks is successful in the long term.

Finding 2: General and specific factors responsible for sustainable ITO success exist.

Finding 3: The ITO model that can aid organisations in planning and implementing ITO solutions by guiding them step-by-step through an ITO project according to general and specific factors relevant for ITO success.

This paper presents the research methodology of this study and each finding in detail.

\section{RESEARCH METHODOLOGY}

The findings are based on an in-depth, multiple case analysis [22] of eight successful long-term application outsourcing cases in five European banks. Table 1 shows the type of the investigated ITO cases and their overall success rating. ITO success was measured qualitatively according to Dahlberg and Nyrhinen [6], by rating each objective for ITO, plus an overall score in a 7-point-Likert scale. Key individuals from the banks, who have previously made ITO decisions or are currently responsible for the ITO's, were interviewed for $1,5-3$ hours. Participants included general manager, division leader IT, subsidiary leader IT, heads of IT department, and heads of vendor management department. Operational units were also invited by the interview partners when necessary. During the interviews, the participants were initially asked to tell their outsourcing story and identify the critical success factors for their case, as a way of summing up the essence of their outsourcing case. Then a series of semistructured questions were asked about the relevance of specific success factors, regardless of whether they had been mentioned in the initial part of the interview. The list of success factors were derived from taxonomies $[9,11,19]$, which were developed in 2009 based on a systematic literature review of 48 scientific publications dealing with ITO outcomes and influencing factors. The list of references was not added for lack of space in this publication but can be requested by the author. The aim of the literature review was to provide a comprehensive picture of success factors, rather than a limited view that was offered in existing literature - scientists mainly investigated the contribution of one or a few factors to ITO success in previous studies or they concentrated on constituent phases of the ITO process. The success factors were derived by qualitative content analysis, and the success factor descriptions were systematically interpreted, condensed, and marshalled in order to obtain common categories. Finally, 10 categories of ITO success factors were derived: environment, strategy, client capabilities, vendor selection, vendor capabilities, contract, stakeholder management, control, co-work, relationship. These constitute the preliminary "theory" that can form the basis for a case study according to Yin [23]. At the end of the interview an open question was asked if additional, not mentioned success factors are to be considered within the scope of the ITO. Thereby it was possible for new, not previously mentioned, factors to emerge. Furthermore, participants were asked to map each relevant success factor in one of the ITO process phases according to Van Lier and Dohmen [20], and to classify them as "mandatory", "partly necessary" or "nice to have". In addition to the interview data, written documentation was gathered as evidence for the statements in the interview: Financial statements, budgets, organisational charts, ITO contracts and service level agreements, due diligence report, annual reports, and reports about service level compliance. In order to ensure precious data, a detailed interview protocol was written by the interviewer and confirmed by the interviewee after the interview. 


\section{Issues in Information Systems}

Volume 13, Issue 2, pp. 369-379, 2012

\section{RESULTS}

Finding 1: Outsourcing of applications by European banks is successful in the long run.

The results of the empirical study show that banks can sustain outsourcing applications in the long run. Eight application outsourcing cases of five well-known European banks were valued as successful (see table 1).

Table 1. Type and outcome of investigated ITO cases

\begin{tabular}{|c|c|c|c|c|c|c|c|}
\hline & $\begin{array}{l}\text { Type of } \\
\text { application }\end{array}$ & Annual costs & $\begin{array}{l}\text { Contract } \\
\text { duration }\end{array}$ & $\begin{array}{l}\text { Years into } \\
\text { contract }\end{array}$ & $\begin{array}{l}\text { Financial } \\
\text { dependency }\end{array}$ & $\begin{array}{l}\text { Delivery } \\
\text { model }\end{array}$ & $\begin{array}{l}\text { Overall } \\
\text { success } \\
\text { rating* }\end{array}$ \\
\hline Application A & $\begin{array}{l}\text { Core Banking } \\
\text { Application }\end{array}$ & not specified & unlimited & $\sim 16$ & External & Onshore & 7 \\
\hline Application B & $\begin{array}{l}\text { Core Banking } \\
\text { Application }\end{array}$ & not specified & unlimited & $\sim 17$ & $\begin{array}{l}\text { External } \\
\text { (formerly equity } \\
\text { holding) }\end{array}$ & Onshore & 6 \\
\hline Application C & Rating Application & $\sim 2,5$ Mio. $€$ & $\begin{array}{l}5 \text { years, } \\
\text { unlimited } \\
\text { prolongation }\end{array}$ & $\sim 6,5$ & Joint Venture & Onshore & 7 \\
\hline Application D & CRM Application & $\sim 2$ Mio. $€$ & unlimited & $\sim 4,5$ & External & Onshore & 5 \\
\hline Application E & $\begin{array}{l}\text { Standard } \\
\text { Application } \\
\text { (personnel } \\
\text { accounting, } \\
\text { inventory) }\end{array}$ & $\sim 3$ Mio. $€$ & unlimited & $\sim 4,5$ & $\begin{array}{l}\text { External } \\
\text { (formerly equity } \\
\text { holding) }\end{array}$ & Onshore & 5 \\
\hline Application F & $\begin{array}{l}\text { Core Banking } \\
\text { Application }\end{array}$ & $\sim 300-400 \mathrm{~T} €$ & $\begin{array}{l}7 \text { years after } \\
\text { prolongation }\end{array}$ & $\sim 14$ & Internal & Nearshore & 7 \\
\hline Application G & $\begin{array}{l}\text { Diverse Banking } \\
\text { Applications }\end{array}$ & not specified & unlimited & $\sim 2$ & Internal & Nearshore & 7 \\
\hline Application $\mathbf{H}$ & $\begin{array}{l}\text { Diverse Banking } \\
\text { Applications }\end{array}$ & $\sim 5$ Mio. $€$ & unlimited & $\sim 7$ & Internal & Nearshore & 5 \\
\hline
\end{tabular}

* According to Dahlberg and Nyrhinen [6] based on a 7 point Likert scale (1: not successful; 7: successful)

The contract terms of the ITO cases at the time of the investigation amounted: 2, 4.5, 6.5, 7, 14, 16 and 17 years.

Four external ITOs, three internal ITOs and one joint venture were the organisational forms of the examined ITO cases. Different kinds of applications were outsourced: Core banking systems, a rating system, a customer relationship management system, a standard system for accountancy, personnel management and goods economy, and others. Strategic, economic, technological and social benefits were achieved by these ITOs: reduction of costs, improvement of cost control, and improvement of business support, improvement of the availability and quality of service, focus on core competencies, access to necessary or new technology and skills, etc. Why are these ITO cases successful?

Finding 2: General and specific factors responsible for sustainable ITO success exist.

Forty general success factors were determined, which were basically relevant in each investigated ITO case.

Also, forty-four specific success factors were determined, which were relevant in certain basic conditions. Certain types of ITOs require, for example, certain success factors. In particular the kind of the outsourced IT function, the organizational form of the ITO, the degree of ITO, the delivery model and the type of vendor could introduce specific success factors. Different ITO objectives can also influence specific success factors. Companies who want to outsource applications are prompted to check if these conditions exist in their case, which would then require the consideration of the specific success factors.

Finding 3: The ITO model that can aid organisations in planning and implementing ITO solutions by guiding them step-by-step through an ITO project according to general and specific factors relevant for ITO success. 


\section{Issues in Information Systems}

Volume 13, Issue 2, pp. 369-379, 2012

This section presents the core factors responsible for ITO success within the ITO model: the general and main specific success factors as per ITO process phase. Figure 1 shows the ITO model with its general success factors in the overview. It also shows the success factor categories, the success factors in short form and the allocation of the success factors to the relevant phases in the ITO process. According to van Lier and Dohmen [20], the ITO process underlying the ITO model contains the following phases: preparation, selection, contract, transition, and execution, post-deal. The preparation phase includes all activities to decide whether ITO should be chosen or not and how to organize ITO. In the selection phase, the best internal or external source for the provision of IT goods and services is detected. The contract phase consists of the contract negotiations with the chosen vendor. The actual transition of IT assets and staff and the establishment of related processes will be realized in the transition phase. The execution phase involves the external execution of the IT function by the vendor according to the contract and boosting of additional benefits on both sides. And finally, in the post-deal phase, the client evaluates if the contract will be extended, if the vendor will be switched or if the outsourced IT function will be brought back in-house. The allocation of the success factors to the relevant ITO process phases is done by marking the small box under the respective process phase grey.

\section{Preparation Phase}

The support of the high-level management on business and IT side towards the ITO is necessary from the start of the ITO project till the contracting phase to receive a positive decision for the ITO and the approval for the completion of the contract. The basic conditions need to be agreed in it as well to guarantee the necessary technical knowhow for a successful ITO project.

The nomination of a project manager for the governance of the ITO project from the preparation phase up to the end of the transition to the vendor, and the specification of the accompanying responsibilities, is a mandatory success factor. The nomination of the project manager and the transference of the competences occur in the preparation phase. In this phase, a company also needs to ensure that it features mandatory capabilities and skills to carry out an ITO project successfully. These are: business knowledge about the business supported by the outsourced IT function, ITO skills, interpersonal skills, organizational learning capability, the capability to cope flexibly with business changes and the capability to solve operational problems rapidly in a multi vendor environment.

In the preparation phase of the ITO process the type of ITO will be decided, which includes the choice of the IT subject (IT function) to be outsourced. Vendor management cannot be outsourced. An ITO does not mean the transfer of the full responsibility and work on the vendor, tight governance and control is necessary on the client side to lead the ITO project to success. Furthermore, the ITO strategy must contain the requirement to renegotiate and restructure the ITO contract early in case of dissatisfaction with vendor performance. Should this not lead to the desired improvement, the cancellation of the ITO contract and the possibility to switch to another vendor need to be included in the ITO strategy as well. This helps to avoid a dependency situation from the current vendor.

The documented identification and the management of ITO risks are compulsory for European banks regarding legal regulations. Before the actual ITO, this is necessary for the benefit of a sound motivation of the ITO, to recognize risks early and to put on measures for the benefit of minimizing risks from the start. The extent of the risk management is to be chosen depending on the risk content of the ITO.

The employees directly affected by the ITO (employees to be outsourced as well as employees remaining in-house and becoming responsible for the control of the ITO) are to be informed openly and honestly before conversion. In particular, a realistic plan of the ITO, the upcoming decisions, the time schedule and the effects on their work are to be communicated. Hence, reliable data must already exist at that time. This requires that vendor evaluations, testing and business case calculations should be done confidentially beforehand. The success factor is therefore relevant from the beginning of the ITO till shortly before completion of the ITO contract. 


\section{Issues in Information Systems}

Volume 13, Issue 2, pp. 369-379, 2012

In the early stages of the ITO (preparation - contracting phase), also the inclusion of relevant business divisions (e.g. human resources, legal department etc.) is to be ensured to consider all relevant aspects and to support a smooth processing of the decision for or against ITO.

\section{Selected Specific Success factors of the ITO Model in the Preparation Phase}

It may seem astonishing, that aspects like an ITO strategy, ITO objectives or business-IT-alignment, which were discussed as relevant for ITO success in previous studies, are not mentioned here; despite these aspects are usually tasks to be done in the forefront of an ITO. These aspects are not rated as generally relevant within the ITO model, as a part of the investigated ITO cases faced changes in strategy, business and ITO objectives which did not lead to the completion of the ITO. These aspects were seen as sensible for direction giving, but not mandatory in case of changes; the fulfillment of the ITO contract was still central.

It could also be ascertained, that IT functions which were seen as impossible to outsource in previous studies (IT management, critical systems, highly interconnected functions), were outsourced in the investigated cases.

The consideration of the user requirements in the forefront of an ITO was also seen as a success relevant aspect in previous studies. This was not confirmed without limitations as well. By use of standard applications not all wishes on functional side could be considered, however, cost savings could be achieved by means of scale effects through standardization. The degree of the implementation of the desired user requirements depended on the strategic significance of the outsourced application, e.g. with distribution relevance of an application or in case of requirements related to legal demands, user requirements became a high priority.

\section{Selection Phase}

The project manager steers the project from his nomination and responsibility transference in the preparation phase of the ITO up to the end of the transition to the vendor.

In the vendor selection phase, the project manager has to ensure that the vendor disposes of mandatory capabilities and skills enabling him to carry out an ITO project successfully. These are: business knowledge about the client's industry, IT knowledge about the outsourced IT function, ITO knowledge, interpersonal skills, organizational learning capability, the capability of a professional staff management in terms of staff quality, capacity, working conditions and allocation, flexibility regarding the implementation of changing client and IT needs, capability of a reliable, professional job completion, financial stability and the capability of a professional cost and financial management, and finally a short response time in case of problems. The fulfilment of legal requirements for outsourced systems is compelling for success during the whole ITO process to maintain the legal capacity of the outsourcing enterprise. Hence, the ability of the vendor to implement these business requirements is to be guaranteed in the vendor selection phase as well.

Different roles need to be assigned and the responsibilities need to be transferred in the vendor selection phase: a notably agreed account manager on the vendor side, relationship managers at the client and vendor side and a service level manager at the client side.

Relationship building and management between client and vendor from the first contact and for the duration of the whole cooperation (selection - execution phase) is mandatory for ITO success. The more in partnership the cooperation is, the more intensely relationship management is to be pursued.

Generally, a regular and effective communication between client and vendor during the time of cooperation is compelling for success with ITO. During the course of the vendor selection phase, the employees in charge of the ITO project need to apply their knowledge on the business supported by the outsourced IT function, ITO in general, and their interpersonal skills to the advantage of the ITO project. 


\section{Issues in Information Systems}

Volume 13, Issue 2, pp. 369-379, 2012

The commitment of the high level management on the business and IT side, the documented identification and management of ITO risks, the information of employees directly affected by the ITO and the involvement of relevant functional departments is also relevant in the vendor selection phase (see preparation phase).

\section{Selected Specific Success Factors of the ITO Model in the Selection Phase}

Success factors mentioned in previous studies, such as a detailed requirements specification or a tendering process with evaluation of internal and external bids do not appear within the general success factors of the vendor selection phase. These factors are specific success factors, as they emerged as just relevant in certain cases. A detailed requirements specification in the selection phase was not accomplished in case of internal ITOs for example, as necessary service adaptations could also be done after contract conclusion, because as a rule influencing possibilities exist due to the capital interlocking between client and vendor. In one internal ITO case the relationship was realised as an external client-vendor relation, which made the success factor relevant again. The accomplishment of a tendering in the vendor selection phase emerged as relevant, if cost reduction objectives stand in the foreground of an ITO. In most investigated cases no tendering was carried out as the vendor was given for strategic reasons. If a tendering was carried out, internal bids were not invited for same reasons.

The switch of long-term employees of the outsourcing enterprise to the vendor by negotiation of secure jobs and good terms of employment is also a specific not a general success factor. Just if know how necessary for the external execution of the outsourced IT function is not available in the market (e.g. ITO of individually developed applications without good system documentation or ITO of standard applications with resource bottlenecks in the market), the outsourcing of long-standing client employees helps to guarantee a smooth start of the ITO.

\section{Contract Phase}

The following general components of the ITO contract have been identified as significant to their long-term success: Obligation to the conversion of legal business requirements in the outsourced IT function, flexibility terms, communication channels between client and vendor (vendors account manager, etc.), a termination clause and the support of the vendor in that case, and control rights for the client and regulatory institutions.

A detailed specification of the service requirements and the linked measures and reports in the ITO contract are not general, but specific success factors, which may be surprising. Under the examined ITO contracts, some did not include detailed service levels. Instead, these were developed successively after contract conclusion. These concerned on the one hand internal ITOs by which service adaptations could be done also after contract conclusion as influencing possibilities exist due to the capital interlocking between client and vendor. In another case of an external sourcing of a standard application with low divergences from the standard functionality, the standard contract of the vendor was originally accepted for the benefit of scale advantages. Necessary adaptations of the service requirements were done afterwards. In case of necessity of anchoring the service level requirements in the contracting phase, the service level manager installed in the selection phase is to be involved already in the service level definition.

Before contract conclusion, external advice is to be engaged in the contracting phase, depending on the experience and missing knowledge of the outsourcing enterprise (legal and technical experts, chartered accountants, tax advisers, etc.).

The following success factors mentioned in the preparation and selection phase are also relevant in the contracting phase: a project manager steering the ITO project, the commitment of the high level management on the business and IT side, the application of business, ITO and interpersonal skills at the client side, a clear and effective communication between client and vendor, relationship building and management, the documented identification and management of ITO risks, the information of employees directly affected by the ITO and the involvement of relevant functional departments. 


\section{Issues in Information Systems}

Volume 13, Issue 2, pp. 369-379, 2012

\section{Selected Specific Success Factors of the ITO Model in the Contract Phase}

Some contract components rated as success relevant in previous studies appeared as not relevant in all cases. These are for example financial penalties. Financial penalties in case of vender underperformance were rated as not relevant in some cases. For example, in case of an external sourcing of a standard application with low divergences from the standard functionality, as the vendor performance was solid regardless. Also financial punishments in a joint venture would curtail the income from investment. Finally, in cases of external ITOs with equity holding, hereby influence possibilities on the vendor based on the capital interweaving can exist, which made the success factor also not relevant. Surprisingly, the success factor was rated as relevant in internal ITO cases, where influence possibilities also exist on the vendor due to a $100 \%$ ownership of the vendor by the client. But internal ITOs can look at financial punishments as necessary contractual mechanism to keep the vendor acting according to the arrangements in the ITO contract despite a certain order situation.

The contractual fixation of regular renegotiation possibilities was also not relevant in each case. In several of these cases no profit achievement intention (e.g. internal ITO, joint venture) existed, only the costs were passed on to the clients. In another case, an external ITO with equity holding to a vendor operating only within a banking group was given. In all of these cases prices are not negotiated between client and vendor, making the success factor not relevant.

\section{Transition Phase}

The regular and strict control of the vendor in the transition and execution phase during the fulfilment of the ITO contract (SLAs, etc.) is crucial for the achievement of ITO success. This is to be done on the basis of a procedure to measure tangible and intangible expectations over a long time-scale. SLA reports can be particularly helpful in recognising if a debasement of the vendor performance occurs, thus allowing early detection and prevention of potential issues.

From the start of the external execution in the transition phase the service level manager acts as a receiver for the agreed service level reports and exercises the regular control of the vendor performance. It appeared that a strict control becomes even more important in case of cultural differences.

A regular reporting of the vendor performance to the management level of the client is necessary in particular in case of insufficient vendor performance. This requires the communication between client and vendor on management levels to positively influence vendor behaviour modification. Partially the management reporting is limited to failure situations with which the general monitoring responsibility is delegated at employee's level.

When using a sourcing network and consequently with availability of several disturbance sources a quick problem solution at the client side is compelling in the transition and execution phase of the ITO process, regardless how it is organized.

The communication channels agreed in the ITO contract, in particular the vendor account manager, are to be used during the external execution which positively influences a common understanding and which prevents vendor opportunism and negative consequences of legal loopholes. Knowledge transferring and sharing between client and vendor is to be promoted actively from the start, in order to positively influence a successful external production of IT goods and services. Vendors should share the necessary knowledge for using the outsourced IT function. Clients should share their business knowledge for improving the vendor's understanding of business requirements. The application of organizational learning capability on the client and vendor side positively influences effective knowledge sharing. Furthermore, the client needs to ensure the acceptance of the vendor in his organization during the external execution of the outsourced IT function.

The following success factors mentioned in the preparation, selection and contracting phase are also relevant in the transition and execution phase: the application of business, ITO and interpersonal skills at the client side, a clear and effective communication between client and vendor, relationship building and management. Risk assessment and 


\section{Issues in Information Systems}

Volume 13, Issue 2, pp. 369-379, 2012

risk management contains in the transition phase mainly the monitoring of the ITO risks. And the commitment of the high level management on the business and IT side refers on the co-carrying of the ITO consequences (e.g. software changes only within agreed release cycles), relationship management at management level and acting as a level of escalation in case of performance disputes.

\section{Selected Specific Success Factors of the ITO Model in the Transition Phase}

Success factors could be determined which are connected with the organizational form of a joint-venture and which were not mentioned up to now in previous literature. These are: a) the formation of working packages for the implementation of the ITO and in case of changes during the external execution, and the distribution of the responsibility for these on the companions; b) a "top balance" between the companions to guarantee a fair price / performance relation with different engagement of the companions; c) a neutral body for the mediation and coordination of votes between the companions; d) regular advisory board meetings during implementation of the ITO and the recruitment of the employees of a joint venture from the market instead of from the companions.

\section{Execution Phase}

All mentioned success factors of the transition phase are also relevant in the execution phase. In addition, the client is recommended to settle payments to the vendor on schedule in case of satisfaction with vendor performance.

Also, the client must cope flexibly with changes of business requirements for the benefit of a permanent and adequate business support. Thereby change project management practices ensuring quality is compelling for ITO success. In particular, re-planning of change projects, management of project risks and construction of an efficient project organization in terms of few involved people at the client and vendor side, are all important abilities to have.

\section{Selected Specific Success Factors of the ITO Model in the Execution Phase}

The regular check of market standards to ensure a competitive cost / benefit-relation of the ITO contract and based on that the initiation of contract adaptations was not a general but a specific success factor. A market comparison was not possible in some cases as no comparable product offer at the market existed or as a market comparison was economically or for technical reasons not feasible 1:1. In another case, the switching of the vendor was not in scope for strategic reasons.

\section{Post-deal Phase}

The main success factor in the post-deal phase is risk assessment and management in terms of the evaluation whether the ITO basically and/or with the current vendor is continued or not. Therefore, the client capabilities, the experiences gained and the people involved in the ITO project needs to be leveraged. 


\section{Issues in Information Systems}

Volume 13, Issue 2, pp. 369-379, 2012

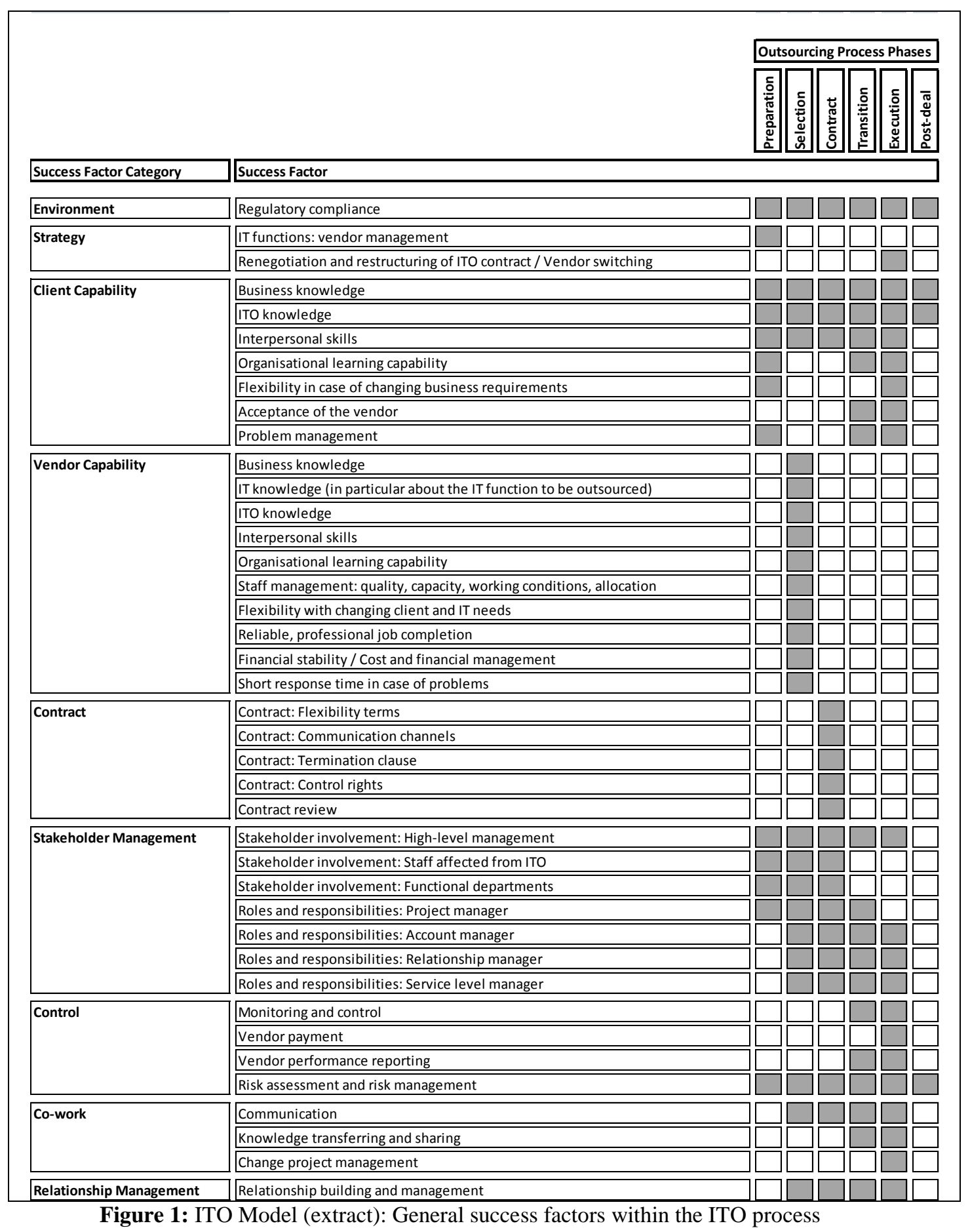

\section{CONCLUSIONS}

A case study research of 8 application long-term ITO cases in 5 European banks clarifies that IT vendors can successfully operate applications externally in the long term. If enterprises are satisfied with their ITOs lasting 


\section{Issues in Information Systems}

Volume 13, Issue 2, pp. 369-379, 2012

effects, then services can be produced permanently by specified external IT service providers in the long run. With it, the industrialization of the IT branch further progresses.

It became evident that some success factors are relevant for all examined ITO cases (general success factors). On the other hand, the relevance of specific success factors depended on the existence of different basic conditions, such as the organisational form of the ITO, the ITO objectives, etc.. New success factors could be determined primarily tied to the organizational form of a joint venture.

The core factors responsible for sustained ITO success are: a) no outsourcing of vendor management; b) client capabilities (business and ITO knowledge, flexibility, problem management, etc.); c) vendor capabilities (IT and ITO knowledge, staff management in terms of quality, capacity, working conditions and allocation, flexibility, financial stability, etc.); d) contract clauses (flexibility terms, communication channels, contract review by external experts, etc.); e) stakeholder involvement (high level business and IT management, staff affected from ITO, functional departments); f) roles and responsibilities (project manager, account manager, relationship managers, service level manager); g) regular monitoring and reporting of vendor performance; $h$ ) vendor payment on time in case of satisfaction; i) effective communication and knowledge transferring and sharing; $j$ ) good change project management; k) risk assessment and risk management; 1) relationship building and management; $\mathrm{m}$ ) renegotiation and restructuring of critical ITO contracts before vendor switching; n) regulatory compliance regarding ITO in general and outsourced applications in particular.

For each success factor it was determined at which time within the ITO process it needs to be considered. This forms an ITO model that can aid organisations in planning and implementing ITO solutions by guiding them step-by-step through an ITO project that comprises of all aspects responsible for long-term success with ITO. This paper presents the core factors responsible for ITO success within the ITO model: general and main specific success factors per ITO process phase.

\section{IMPLICATIONS FOR FUTURE RESEARCH}

This study has focused on the investigation of application outsourcing by banks in order to guarantee a comparability of the research results. Hence, the ITO model is applicable to this type of IT function. The applicability for the complete ITO area requires the test of the ITO model for other types of IT functions (infrastructure, business processes) and for other branches. The investigation of the ITO model with ITO cases from other areas supports the development of an ITO theory. The empirical research uncovered new success factors previously not discussed in research literature, whose relevance depends mainly on the organisational form of a joint venture. Testing these new success factors with further ITO cases of this organizational form is recommended in future research to support their generalization.

The following recommendations are given for future success factor research in the IT outsourcing field:

- The ITO model contains a big number in empirically validated success factors of different kinds. In addition, these success factors are partially dependent on each other. Hence, future researchers should renounce the investigation of single success factors or smaller groups of success factors. Instead a comprehensive approach is to be applied which considers the test of all determined success factors and success factor dependencies in order to explain ITO success.

- Views on the relevance of certain factors for the achievement of ITO success differ in previous research. This study has shown that the relevance of some success factors (specific success factors) depends on the existence of certain basic conditions, in particular from the chosen kind of the ITO (organizational form, delivery model, etc.). Former studies do not consider these use cases that could explain the divergences. Hence, future success factor research should take into account the determined success factor use cases in the discussions.

This study has shown that eight IT applications of different strategic significance could be outsourced successfully in the long-term. This result points in the direction that the industrialization of the IT sector further progresses. But the detection and examination of other long-term ITO cases is necessary since only if a bigger number of enterprises 


\section{Issues in Information Systems}

Volume 13, Issue 2, pp. 369-379, 2012

outsource successfully in the long term, can this increase the likelihood of a lasting production of IT goods and services by IT vendors.

\section{REFERENCES}

1. Encyclopedia Britannica (1991). Encyclopedia Britannica. Chicago.

2. Brockhaus, F.A. (1989). Brockhaus-Enzyklopädie.

3. Carr, N. (2003). It doesn't matter. Harvard Business Review, May, 1-11.

4. Carr, N. (2005). The End of Corporate Computing. MIT Sloan Management Review, 46(3), 67-73.

5. Clark Jr., T.D. (1995). The outsourcing of information services: transforming the nature of business in the information industry. Journal of Information Technology, 10, 221-237.

6. Dahlberg, T. and Nyrhinen, M. (2006). A New Instrument to Measure the Success of IT Outsourcing. Proceedings of the 39th Hawaii International Conference on System Sciences.

7. Dibbern, J., Goles, T., Hirschheim, R. and Jayatilaka, B. 2004. "Information Systems Outsourcing: A Survey and Analysis of the Literature, The DATA BASE for Advances in Information Systems (35:4), p. 87.

8. Fraunhofer IAO 2005. Bank \& Zukunft 2005: Trends und Entwicklungen im Front- und Back-Office-Bereich von Banken in Deutschland: Trendstudie, Fraunhofer-Institut für Arbeitswirtschaft und Organisation, Stuttgart.

9. Hambrick, D.C. (1984). Taxonomic Approaches to Studying Strategy: Some Conceptual and Methodological Issues. Journal of Management, 10(1), 27-41.

10. Kern, T.; Willcocks, L. P. (2001). The Relationship Advantage: Information Technologies, Sourcing, and Management. Oxford: Oxford University Press.

11. Kluge, S. (1999). Empirisch begründete Typenbildung. Zur Konstruktion von Typen und Typologien in der qualitativen Sozialforschung. Opladen: Leske und Budrich.

12. Koh, C.; Ang, S.; Straub, D. W. (2004). IT Outsourcing Success: A Psychological Contract Perspective. Information Systems Research, 15(4), 356-373.

13. Lacity, M. and Willcocks, L. (1998). An empirical investigation of information technology sourcing practices: lessons from experiences. MIS Quarterly, September, 363-409.

14. Lacity, M. C.; Willcocks, L. P. (2009a). Transaction Cost Economics Applied to IT Outsourcing: Findings and Critique. In: Information Systems and Outsourcing, Lacity, M. C. and Willcocks, L. P. Eds., Basingstoke, Hampshire: Palgrave Macmillan.

15. Lacity, M. C.; Willcocks, L. P. (2009b). Managing Relationships across the life Cycle of an Outsourcing Arrangement. In: Information Systems and Outsourcing, Lacity, M. C. and Willcocks, L. P. Eds., Basingstoke, Hampshire: Palgrave Macmillan.

16. Mahnke, V., Overby, M. L. and Vang, J. 2005. "Strategic Outsourcing of IT services; Theoretical Stocktaking and Empirical Challenges", Industry and Innovation (June).

17. Matiaske, W. and Mellewigt, T. 2002. "Viel Lärm um Nichts - Rückblick auf ein Jahrzehnt empirischer Outsourcing-Forschung“, Organisatorische Veränderung und Corporate Governance (1:288), Egbert, K. Wiesbaden, Deutscher Universitäts-Verlag GmbH.

18. Pütter, C. (2011). IT Outsourcing Anbieter: Kampf um Neukunden beginnt. IDG Business Media GmbH, Available: http://www.cio.de/knowledgecenter/outsourcing/2288003/.

19. Rich, P. (1992). The organizational taxonomy: Definition and design. Academy of Management Review, 17(4), 758.

20. Van Lier, J. and Dohmen, T. (2007). Benefits Management and Strategic Alignment in an IT Outsourcing Context. IEEE.

21. Veltri, N.; Saunders, C. S.; Kavan, C. B. (2008). Information Systems Backsourcing: Correcting Problems and Responding to Opportunities. California Management Review, 51(1).

22. Yin, R.K. (1989). Case Study Research - Design and Methods. Applied social research methods Series, 5, Newbury Park, California: Sage Publications Inc.

23. Yin, R.K. (1993). Applications of Case Study Research. Applied social research methods series. 34, Newbury Park, California: Sage Publications Inc. 